\title{
Teses e dissertações do Programa de Pós-Graduação em História, Política e Bens Culturais do CPDOC/FGV defendidas em 2011
}

1. Mapeamentos musicais no Brasil - três experiências em busca da diversidade

Helena de Moura Aragão

Defesa: 02/03/2011 - Mestrado Acadêmico

Banca: Lucia Maria Lippi de Oliveira (orientadora), Bernardo Buarque de Hollanda (CPDOC/FGV), Santuza Naves (PUC-RIO) e Paulo Fontes (CPDOC/FGV)

Resumo: O presente trabalho se dedica a refletir sobre experiências de pesquisa com pretensões de mapeamento musical do Brasil: Música Popular do Brasil, da gravadora Discos Marcus Pereira, no decorrer dos anos 1970, e Música do Brasil, realizado pelo antropólogo Hermano Vianna e o músico Beto Villares no final dos anos 1990, ambos com fortes influências da Missão de Pesquisas Folclóricas, idealizada por Mário de Andrade no fim dos anos 1930. Estes não foram os únicos projetos com objetivo de registrar gêneros de todo o país, mas, em três momentos diferentes do século XX, buscaram vincular a noção de diversidade musical ao conceito de identidade nacional. As continuidades e rupturas entre eles, além do diálogo de cada um com o contexto de sua época, são os principais pontos de interesse desta dissertação. 
2. Tribuna de Petrópolis: Trajetória e representação da Cidade Imperial:

Imprensa e identidade de Petrópolis em 100 anos de jornal local

Verônica Soares da Costa

Defesa: 25/03/2011 - Mestrado Profissional

Banca: Fernando Lattmann-Weltman (orientador), Marieta de Moraes

Ferreira(CPDOC/FGV), Ana Paula Goulart (ECO/UFRJ) e Bernardo Buarque de Hollanda (CPDOC/FGV)

Resumo: Fundada em 1902, a Tribuna de Petrópolis acumula 108 anos de publicação na cidade serrana do interior do Estado do Rio de Janeiro. Sendo um jornal local, de circulação restrita aos limites do município, sua existência por mais de um século reflete o esforço de seus diretores pela superação de crises e também pela manutenção de um poder simbólico de identidades sobre a cidade. Analisa-se a trajetória do jornal a partir de três fases de existência e da relação que estabeleceu com Petrópolis em cada uma delas: no início do século XX, quando de sua fundação, momento em que representa o reposicionamento político do Grupo de Petrópolis, após a perda da capital para Niterói; na metade do século, entre os anos 1950 e 1970, quando o jornal atravessa uma profunda crise e tem sua falência decretada; e nas décadas finais do século XX, quando o veículo se reorganiza e, sob o comando de herdeiros da Família Imperial, constrói para si uma nova relação de identificação e representação com a cidade de Petrópolis. Como jornal-empresa e parte de um conglomerado de comunicação, a Tribuna de Petrópolis chega ao século XXI e se estabelece como instituição pautada por escolhas e decisões estratégicas de administração e relacionamento com o mercado local de anunciantes.

3. Desenhando um paraíso tropical: a construção do Rio de faneiro como um destino turístico

Isabella Perrota

Defesa: 28/03/2011 - Doutorado

Banca: Celso Castro (orientador), Angela Maria de Castro Gomes

(CPDOC/FGV), Bianca Freire Medeiros (CPDOC/FGV), Maria Inez Turazzi Museu Imperial), Doris Kominsky (UFRJ), Bernardo Buarque de Hollanda (CPDOC/FGV) e Claudio Magalhães (PUC)

Resumo: As primeiras imagens (gráficas ou narrativas) que circularam no exterior sobre o Rio de Janeiro. O complexo processo de produção em série da imagem, envolvendo vários profissionais que muitas vezes trabalhavam à dis- 
tância. As possibilidades econômicas de uma cidade a ser construída, e o interesse de imigrantes aventureiros e empreendedores. A cidade que os primeiros guias para viajantes pretendiam mostrar. A modernização da urbe, voltada para o olhar internacional. A construção da identidade nacional pela música, pela dança e pela indústria do entretenimento. A identificação do carioca com os estereótipos que lhe foram concedidos. A perpetuação dos ícones da cidade. Este trabalho perpassa várias categorias temáticas, buscando revelar o processo de construção da cidade do Rio de Janeiro enquanto um destino turístico. Um paraíso tropical a ser conhecido.

4. O que fazer com os rudes? Isaías Alves e as divergências sobre o papel da inteligência na organização escolar (1930-1942)

Ana Cristina Santos Matos Rocha

Defesa: 28/03/2011 - Mestrado Acadêmico

Banca: Helena Maria Bomeny (orientadora), Libânia Xavier (UFRJ), Maria Helena Magalhaes Castro (UFRJ) e Americo Oscar Freire (CPDOC/FGV)

Resumo: Entre 1930 e 1942, período em que esta pesquisa se concentra, Isaías Alves participou do debate sobre a política educacional a ser adotada pelo Brasil. Também atuou em diversas instâncias de organização e administração pública, como a Diretoria Geral de Instrução Pública do Rio de Janeiro e a Secretaria de Educação e Saúde da Bahia. Este educador, no entanto, ficou conhecido por suas atividades posteriores a 1942, quando fundou a Faculdade de Filosofia da Bahia. Esta pesquisa investiga a trajetória de Isaías Alves e suas experiências desenvolvidas com testes de inteligência nas escolas primárias, que serve como ponto de partida para explorar sua atuação como educador e como intelectual. Ao mesmo tempo, explora o debate gerado em torno da adoção dessa ferramenta de avaliação, que prometia transformar o ambiente escolar ao uniformizar as classes escolares a partir do potencial de aprendizagem de cada criança, a ser aferido pelos testes. Essa discussão se insere no contexto de expansão do sistema educacional brasileiro, que tinha entre seus objetivos aumentar a eficiência escolar. Assim, o uso de testes de inteligência nas escolas se apresentou como um dos caminhos para aperfeiçoar o ensino no país.

5. A LDB de 1961: conceitos, representações e confrontos no campo político-pedagógico

Sérgio Montalvão

Defesa: 29/03/2011 - Doutorado 
Banca: Helena Maria Bomeny (orientadora), Angela Maria de Castro Gomes (CPDOC/FGV), Marly Motta (CPDOC/FGV), Ana Maria Magaldi (UERJ), Luiz Antonio Cunha (UFRJ) e Christiane Jalles de Paula (CPDOC/FGV)

Resumo: A História da Educação ainda é um campo praticamente inexplorado pelos historiadores de ofício. Francisco Falcon (2006) reforçou essa constatação ao tratar do desinteresse da história cultural em relação à história das práticas educacionais, apesar das imensas afinidades entre os seus objetos de estudo. As tradições e querelas disciplinares, segundo o argumento do historiador, explicam essa ausência. A História da Educação não foi instituída como especialização temática da história, mas como ciência da educação ou ciência auxiliar da educação (Falcon, 2006: 331). E nessa condição, a disciplina nasceu para identificar os erros e acertos de experiências pedagógicas passadas, carregando, em seu percurso inicial, a marca do pragmatismo e da exemplaridade (Warde, 1990).

\section{Desatando os nós: uma experiência do Serviço Social na área da Educação e da Cultura}

Fabrícia Vellasquez Paiva

Defesa: 25/03/2011 - Mestrado Profissional

Banca: Helena Maria Bomeny(orientadora), Americo Oscar Freire (CPDOC/FGV), Vanda Maria Ribeiro Costa (UERJ) e Paulo Fontes (CPDOC/FGV)

Resumo: Esta pesquisa aborda a aproximação entre Serviço Social e Educação, tendo como viés diretivo a cultura. Focaliza a relação entre as áreas a partir de um estudo de caso, cuja intervenção ocorreu por meio de um projeto de extensão universitária - o Projeto de Extensão Educação Pública e Serviço Social (PEEPSS) - oferecido sob a coordenação de um professor pioneiro nesta discussão no âmbito da Universidade do Estado do Rio de Janeiro (UERJ). Este trabalho se situa com olhar em um subprojeto do PEEPSS - Educação, Cultura, Universidade e Serviço Social (ECUSS) - mais especificamente em um trabalho realizado com a ONG Nós do Cinema (NDC). Por ser também um campo de estágio supervisionado aos graduandos em Serviço Social da UERJ, a metodologia utilizada neste trabalho priorizou a análise do discurso de alguns relatórios de estágio, seguida de entrevistas ao coordenador do projeto, bem como aos mesmos supervisionados que tiveram seus documentos de estágio analisados. A pesquisa apresenta elementos de interseção entre as áreas mencionadas, procurando discutir sobre a formação profissional para tal abordagem cultural, assim como o debate acerca dos campos de prática na área da Educação e da Cultura para o assistente social. 


\section{Integração de políticas sociais: um estudo de caso sobre o Bolsa-Família}

Iraneth Rodrigues Monteiro

Defesa: 29/03/2011 - Mestrado Profissional

Banca: João Marcelo Ehlert Maia (orientador), Leandro Molhano Ribeiro

(FGV/Direito Rio), Alexandre Fortes (UFRRJ) e Paulo Fontes (CPDOC/FGV)

Resumo: O presente trabalho propõe-se a analisar o processo de integração das diversas ações de transferência de renda no âmbito do governo federal, durante a primeira gestão do presidente Luiz Inácio Lula da Silva, entre os anos de 2003 e 2006, que resultou na criação do Programa Bolsa Família. A análise proposta busca contribuir para ampliar o conhecimento sobre o governo e a administração pública, gerando informações sobre a formação da agenda governamental de um governo comprometido, programaticamente, com a redução da pobreza e da desigualdade social. Quanto ao caminho metodológico percorrido, na elaboração desta dissertação, partiu-se da seguinte pergunta-chave: por que e como se deu o processo de integração do Programa Bolsa Família? A metodologia de pesquisa aplicada consistiu na identificação das razões para a entrada deste tema na agenda governamental do primeiro governo do presidente Lula. Para tanto, foi realizado um estudo de caso, objetivando identificar quais atores participaram da discussão sobre a unificação dos programas de transferência de renda e quais foram os conceitos que os orientaram. Como instrumento de pesquisa, optou-se pela aplicação de entrevistas semi-estruturadas com alguns participantes do Grupo de Trabalho de Unificação dos Programas de Transferência de Renda. Além das entrevistas, as outras fontes utilizadas foram: os relatórios e/ou atas das reuniões do Grupo de Trabalho, da Câmara de Política Social do governo; as legislações dos programas anteriores; a legislação do Programa Bolsa Família; os discursos realizados pelo presidente eleito Luiz Inácio Lula da Silva entre janeiro e outubro de 2003. Por meio da análise, de toda a documentação elencada, é possível verificar o esforço governamental no sentido de implementar mudanças nos programas de transferência de renda. Dessas reuniões foram produzidos relatórios pelos Grupos Técnicos, abordando as políticas sociais para a redução das desigualdades, construindo o Programa Bolsa Família e levando-se em conta a importância do legado histórico das ações existentes. Como resultado da pesquisa, identificou-se que o presidente Lula, a Câmara de Política Social e o seu grupo de especialistas técnicos souberam aproveitar a janela de oportunidades de um governo que estava iniciando com forte apelo para desenvolver políticas públicas de combate à fome e à pobreza. Após percorrer o caminho de reconstrução histórica para a elaboração dessa dissertação, buscou-se destacar algumas contribuições que tem por objetivo servir de incentivo para novos estudos sobre o processo decisório na esfera pública de governo. 


\section{Leituras brasileiras sobre a nova ordem internacional}

Andrea de Oliveira Ribeiro

Defesa: 30/03/2011 - Mestrado Acadêmico

Banca: João Marcelo Ehlert Maia (orientador), Matias Spektor

(CPDOC/FGV), Maurício Santoro (UCAM) e Cláudio Pinheiro Costa (CPDOC/FGV)

Resumo: O presente trabalho é resultado de pesquisa realizada a respeito das leituras brasileiras sobre a Nova Ordem Internacional. A partir da investigação em fontes históricas depositadas no Centro de Pesquisa e Documentação em História Contemporânea do Brasil (CPDOC/FGV), como os documentos textuais do Arquivo Marcílio Marques Moreira e as entrevistas de Celso Amorim, Celso Lafer, Gelson Fonseca e Luiz Felipe Lampreia, procurou-se analisar as principais ideias de três personagens históricos diretamente envolvidos com a formulação da política externa brasileira no período da Nova República, mais especificamente entre 1989 e 1994: Celso Lafer, Gelson Fonseca e Rubens Ricupero. Para tanto, buscou-se destacar as principais formas de interpretação do sistema internacional alterado pelo fim do conflito bipolar com o apoio da literatura mais recente produzida na área, como os trabalhos de Odd Westad (2005), Andrew Hurrell (2001, 2007) e John Ikenberry (2005). Os dados coletados durante o processo de feitura da pesquisa permitem-nos afirmar que, no Brasil, os temas da autonomia e do desenvolvimento são resilientes. Os debates sobre autonomia e desenvolvimento - tão caros ao discurso acadêmico e político nacionalista desenvolvido nos anos 50 , além de terem permanecido como preocupação de fundo nas análises dos formuladores de política externa - demonstram que, no Brasil, o discurso modernizante retomou as ideias básicas do pensamento político nativo.

\section{Palácio Rio Branco: O palácio que virou museu}

Ana Paula Bousquet Viana

Defesa: 31/03/2011 - Mestrado Profissional

Banca: Lucia Maria Lippi de Oliveira (orientadora), Bianca Freire-Medeiros (CPDOC/FGV), Regina M. Abreu (UFRJ) e João Marcelo Ehlert Maia (CPDOC/FGV)

Resumo: Este trabalho tem por objetivo recuperar parte da trajetória do Palácio Rio Branco que virou museu, por se tratar de um forte símbolo cultural 
na sociedade acreana. A pesquisa tem como foco a criação, em 2002, de um museu nas dependências do Palácio Rio Branco. A partir de sua exposição permanente e de seu acervo, convido o leitor a uma imersão em parte da história da formação e do povoamento do Acre. A pesquisa se destina acima de tudo a divulgar o estado do Acre e sua cultura e o Palácio como símbolo maior da sociedade acreana e do museu.

10. Aqui você faz a notícia: mídia e jornalismo cidadão nas páginas do "Eu-Repórter"

Adriana Silva do Nascimento

Defesa: 29/4/2011 - Mestrado Acadêmico

Banca: Fernando Lattman-Weltman (orientador), Paulo de Mesquita D'Ávila (PUC-RJ), Ludmila Ribeiro (CPDOC/FGV) e Mariana Cavalcanti (CPDOC/FGV)

Resumo: Apresentando um percurso histórico que mostra a configuração do jornalismo como atividade profissional e empresarial, o presente trabalho desenvolve uma reflexão sobre a produção jornalística aberta à participação do indivíduo sem formação de jornalista para se chegar a um modelo de jornalismo cidadão no qual as notícias são pautadas pelo interesse público e colaboram para o reforço da visibilidade pública e do acesso à informação que fomenta a deliberação. Através da análise do canal de jornalismo aberto Eu-Repórter, observa-se que o exercício do modelo proposto de jornalismo cidadão torna-se inviável em uma iniciativa ligada a um veículo de comunicação da mídia tradicional, porque a notícia passa por filtros construídos através de uma lógica de mercado que prevê interesses políticos e econômicos alheios a um papel da mídia como espaço de debate público ampliado.

11. Os alunos do Colégio Estadual Souza Aguiar e a apropriação do patrimônio cultural da Lapa: um estudo de caso

Evandro Luiz de Carvalho

Defesa: 04/04/2011 - Mestrado Profissional

Banca: João Marcelo Ehlert Maia (orientador), Luciana Quillet Heymann (CPDOC/FGV), Marcelo Baumann Burgos (PUC-RJ) e Paulo Fontes (CPDOC/FGV)

Resumo: A presente pesquisa coloca em foco a relação dos alunos do Colégio Souza Aguiar com o patrimônio edificado da Lapa, investigando os signifi- 
cados desses bens para os jovens estudantes do colégio. Este trabalho valeu-se das contribuições teóricas de Michel de Certeau, no que concerne aos estudos da produção dos consumidores através de suas táticas nos usos e contra-usos do espaço urbano. Considerando os discentes inseridos num espaço patrimonializado, buscou-se compreender como os jovens se apropriam desses bens através de suas práticas cotidianas. Valendo-se ainda das reflexões de Pierre Nora, investigou-se a propriedade do conceito de lugar de memória aplicada ao patrimônio histórico da Lapa e à população estudada. Analisando ainda a receptividade do patrimônio pela população em foco, recorreu-se aos estudos sobre ressonância de José Reginaldo Gonçalves. Do mesmo autor, foram relevantes as reflexões sobre o conceito de objetificação cultural para a apreciação dos discursos oficiais sobre o patrimônio. Como produto final dessa pesquisa, apresenta-se um termo de referência para um projeto em educação patrimonial, que tem como objetivo inserir os jovens alunos do Colégio Souza Aguiar na discussão sobre o patrimônio histórico da Lapa.

\section{A avaliação de impactos ambientais e o licenciamento ambiental no Brasil:} reflexões a partir do caso do Complexo Terrestre Cyclone 4

Carlos Eduardo Caldarelli

Defesa: 14/04/2011 - Mestrado Profissional

Banca: Luciana Quillet Heymann (orientadora), Mario Grynszpan (CPDOC/FGV), José Maurício Andion Arruti (PUC-RJ) e Mariana Cavalcanti (CPDOC/FGV)

Resumo: Esta dissertação trata da avaliação de impacto ambiental e das suas relações com o procedimento de licenciamento ambiental. Procura-se mostrar de que modo ambos manifestam-se metodológica e procedimentalmente no processo histórico e são permeados pela política. Em primeiro lugar, são expostos e discutidos os fatos que cercaram a inclusão da metodologia da avaliação de impacto ambiental no procedimento de licenciamento ambiental, no Brasil. Também a metodologia da avaliação de impacto ambiental e $o$ atual procedimento de licenciamento ambiental brasileiro são detalhados e discutidos. Após isso, estuda-se o caso do licenciamento ambiental do Complexo Terrestre Cyclone 4, que leva à discussão acerca de como a legitimação de hierarquias que privilegiam o conhecimento científico e tecnológico em relação aos saberes locais tem sido combatida e subvertida ou, por outro lado, tem prevalecido, nos procedimentos de licenciamento ambiental e nas avaliações de impacto ambiental que ocorrem, presentemente, no Brasil. 
13. Advocacia em tempos sombrios: de como um grupo de advogados enfrentou a ditadura militar de 1964

Denise Dourado Dora

Defesa: 06/05/2011 - Mestrado Acadêmico

Banca: Mario Grynszpan (orientador), Dulce Chaves Pandolfi (CPDOC/FGV), Maria Celina D’Araújo (PUC-RJ) e Américo Oscar Freire (CPDOC/FGV)

14. Manuelzão: uma experiência de militância e jornalismo

Marco Antônio Pessoa Veloso de Almeida Defesa: 15/04/2011 - Mestrado Profissional Banca: Christiane Jalles de Paula (orientadora), Dulce Pandolfi (CPDOC/FGV), Ricardo Fabrino de Mendonça (UFMG) e Mário Grynszpan (CPDOC/FGV)

Resumo: Neste trabalho, procuramos fazer algumas reflexões sobre a apropriação da linguagem jornalística por uma instituição envolvida em uma luta social como instrumento para discursar na esfera pública. Para isso, utilizamos como objeto de estudo o jornal e a revista do Projeto Manuelzão, uma organização que surgiu como uma atividade de extensão da Universidade Federal de Minas Gerais (UFMG), mas que conseguiu ultrapassar os muros da universidade e tornar-se uma das mais importantes instituições que milita na área ambiental no estado de Minas Gerais. Procuramos identificar como o veículo constrói representações do Projeto Manuelzão enquanto ator político. Também estudamos as formas como o veículo apresenta os argumentos da instituição sobre um tema específico: a transposição do rio São Francisco.

15. Entre grãos e pixels, os dilemas éticos na restauração de filmes: o caso de Terra em Transe

Marco Dreer Buarque

Defesa: 27/04/2011 - Mestrado Profissional

Banca: Monica Almeida Kornis (orientadora), Mariana Cavalcanti (CPDOC/FGV), João Luiz Vieira (UFF) e Bernardo Buarque de Hollanda (CPDOC/FGV)

Resumo: A restauração de filmes no Brasil se tornou uma atividade mais sistemática a partir dos anos 1990, com a introdução das ferramentas digitais. Ao 
mesmo tempo em que trouxeram uma possibilidade quase ilimitada de intervenção nos filmes, as ferramentas digitais introduziram também um debate acerca da natureza ética envolvendo a restauração de filmes. Nesse contexto, destacam-se os projetos de restauração dedicados aos filmes do Cinema Novo. Este trabalho pretende verificar em que medida a restauração digital vem a afetar os elementos de linguagem de Terra em Transe, de Glauber Rocha, filme marcado por uma grande inventividade formal. A análise da restauração do filme foi pautada por alguns dos conceitos de Cesare Brandi, autor que procurou trabalhar com a questão da ética no campo das artes plásticas. Algumas questões relacionadas à ética e à conceituação de restauração, bem como à trajetória histórica da restauração de filmes no Brasil, também são debatidas no texto.

16. Procurando caminhos, revelando descaminhos: consumo de filmes entre jovens estudantes da rede estadual fluminense

Maria Rodrigues Pereira

Defesa: 18/04/2011 - Mestrado Profissional

Banca: Mariana Cavalcanti (orientadora), Bernardo Buarque de Hollanda (CPDOC/FGV), Carlos Eduardo Machado Fialho (UFF) e Claudio Costa Pinheiro (CPDOC/FGV)

Resumo: O presente trabalho tem por objetivo conhecer a cultura cinematográfica de jovens estudantes da rede estadual de ensino do Rio de Janeiro. Para tanto, analisa o contexto em que se formam espectadores e investiga seus hábitos, práticas e demandas de consumo. Procurou-se levantar e sistematizar dados sobre as formas como esse público escolhe e se apropria dos filmes e sobre os circuitos à disposição, e correlacioná-las com a configuração do panorama de produção e difusão do setor cinematográfico e audiovisual. A pesquisa confere também destaque às percepções e demandas relativas à atual produção cinematográfica brasileira.

17. As cidades, a cidade. Política, Arquitetura e Cultura na Cidade do Rio de Faneiro

Paula de Oliveira Camargo

Defesa: 05/05/2011 - Mestrado Profissional

Banca: Américo Oscar Freire (orientador), Lucia Maria Lippi de Oliveira (CPDOC/FGV), Margareth Pereira (UFRJ) e Mariana Cavalcanti (CPDOC/FGV) 
Resumo: A cidade do Rio de Janeiro passou, ao longo de sua história, por diversos processos de renovação e reestruturação urbana, com abordagens e enfoques diferenciados. Esses processos trouxeram mudanças profundas ao traçado original da cidade e aos usos de cada região, inclusive com a introdução da noção de zoneamento. A evolução tecnológica, a conteinerização da economia dos portos e a obsolescência de equipamentos, bem como a redução da atividade portuária na cidade, fizeram com que áreas expressivas se tornassem quase que inteiramente obsoletas, como foi o caso da região do Porto do Rio.

\section{Uma análise da construção do Museu de Arte do Espírito Santo e} de seus reflexos

Rafaela Rasseli Zanete

Defesa: 01/07/2011 - Mestrado Profissional

Banca: João Marcelo Ehlert Maia (orientador), Lucia Maria Lippi de Oliveira (CPDOC/FGV), Sabrina Marques Parracho Sant'Anna (UFFRJ) e Paulo Fontes (CPDOC/FGV)

Resumo: Esta pesquisa apresenta alguns dados do processo de construção do Museu de Arte do Espírito Santo - MAES até a sua inauguração e uma análise atual, refletindo sobre o papel do poder público através do estudo de matérias de jornais e entrevistas com alguns atores participantes do processo de discussão e instalação do MAES, e o posicionamento adotado pelo governo ao longo deste período, bem como o da classe artística e da sociedade em geral. Pretendeu-se reconhecer os atores participantes de todo esse processo recorrendo a documentos que explicitassem as relações que existiram nesse período entre os poderes públicos, os interesses da classe artística e os da coletividade que fez e faz uso da instituição. Ao final, mostra-se como esses discursos influenciam o museu até os dias de hoje. Para tal, inscrevemos nossa discussão sobre o MAES no âmbito de uma reflexão mais geral sobre os museus na atualidade.

\section{Parque Nacional da Serra da Capivara: patrimônio cultural da humanidade}

\section{Adriana Maria Ferreira Martins}

Defesa: 16/08/2011 - Mestrado Profissional

Banca: Lucia Maria Lippi de Oliveira (orientadora), Marieta de Moraes

Ferreira (CPDOC/FGV), Adauto José Gonçalves de Araujo (FIOCRUZ) e João Marcelo Ehlert Maia (CPDOC/FGV)

Resumo: O presente trabalho tem como objetivo analisar o Parque Nacional da Serra da Capivara desde sua criação à situação atual a fim de compreen- 
der as razões que até hoje impedem o seu pleno funcionamento. Para tanto, foram analisados aspectos anteriores à constituição do Parque, desde as primeiras expedições da Missão Franco-Brasileira no Piauí, até itens como infraestrutura, equipamentos e potencial turístico oferecidos atualmente pelo Parque. Aliado a esse estudo, foram colhidos depoimentos, entre eles, de alguns dos atores diretamente envolvidos no desenvolvimento do Parque. O resultado é um panorama histórico que explica as circunstâncias que fazem do Parque Nacional Serra da Capivara Patrimônio Cultural da Humanidade.

\section{A Política Cultural do Conselho Federal de Cultura, 1966-1976}

Lilian Araripe Lustosa da Costa

Defesa: 22/08/2011 - Mestrado Acadêmico.

Banca: Lucia Maria Lippi de Oliveira (orientadora), Angela de Castro Gomes(CPDOC/FGV), Lia Calabre (Casa de Rui Barbosa) e João Marcelo Ehlert Maia (CPDOC/FGV)

\section{Relíquias da nação: a proteção de coleçães e acervos no patrimônio} (1937-1979)

Tatiana Costa Sena

Defesa: 23/8/2011 - Mestrado Acadêmico

Banca: Lucia Maria Lippi de Oliveira (orientadora), Luciana Quillet Heyman (CPDOC/FGV), Letícia Julião (UFMG) e Bernardo Buarque de Hollanda (CPDOC/FGV)

Resumo: Realizamos uma investigação acerca do tombamento de coleções e acervos abrangendo as duas primeiras gestões do órgão do patrimônio nacional (1937-1979). Escolhemos este período por ser neste que ocorre o empenho na proteção desses bens móveis em conjunto, ou seja, dos acervos e coleções. Nossa intenção é descrever como o campo do patrimônio - institucionalizado no Brasil na década de 1930, com a criação do Serviço de Patrimônio Histórico e Artístico Nacional (SPHAN) - atuava na preservação de coleções e acervos tombados. Ao lado do tombamento, considerado como medida de proteção para esses bens, o SPHAN procurou desenvolver outras ações para a proteção de bens móveis, como o cadastro de negociantes de obras de arte e o inventário de colecionadores particulares. Essas iniciativas foram tomadas sobretudo a partir da contribuição do SPHAN em terras paulistas, na gestão de Mário de Andrade e do 
arquiteto Luis Saia, foco principal do nosso estudo. Assim, esses objetos são preservados e protegidos pelo órgão de patrimônio por serem dotados de valor de raridade e de documento, constituindo valiosas fontes para conhecer e difundir a memória nacional, garantindo assim, esse legado ao tempo.

\section{Lições vivas da História do Brasil: educar e comemorar no Museu Mariano Procópio}

Carina Martins Costa

Defesa: 02/09/2011 - Doutorado

Banca: Angela de Castro Gomes (orientadora), Lucia Maria Lippi de Oliveira (CPDOC/FGV), Cecília Helena de Salles Oliveira (USP), Mário Souza Chagas (UNIRIO), Regina Maria do Rego Monteiro Abreu (UNIRIO) e Marly da Silva Motta (CPDOC/FGV)

Resumo: Esta tese é uma reflexão sobre a construção de escritas da História do Brasil em museus, a partir da década de 1920, momento fulcral para o estabelecimento de uma "pedagogia da nacionalidade" republicana, que tem por suporte o discurso museal. Alguns dos esforços político-pedagógicos dessas instituições foram observados, com o objetivo de compreender as principais características de um paradigma educativo para o saber histórico nos museus. Assim, a análise das comemorações cívicas, dos guias de divulgação e das exposições permitiu uma aproximação das ativações memoriais ensejadas pelos atores dos museus, com atenção para as continuidades, as negociações e as transformações dos projetos, especialmente em sua dimensão pedagógica. O Museu Mariano Procópio foi selecionado para a realização de um estudo de caso, tanto por suas especificidades, que nos induzem a pensar o "concerto" dos museus nacionais a partir do interior do país, como pela relevância de seu acervo e pela intensidade de ações educativas desenvolvidas na gestão de Geralda Armond (1944-1980). A gestão Armond é o foco da tese, sendo marcada pela defesa da continuidade institucional e do enquadramento da memória da família Lage; pela luta pela sustentação material do Museu, inclusive com uma forte aproximação com o regime civil e militar; e pela busca da profissionalização de quadros e do dinamismo das ações. Os resultados atentam para a multiplicidade e fragilidade na construção identitária do Museu, associada ao fato de ser um museu "municipal”. Uma situação que explica, ao menos em parte, seu esquecimento no cenário nacional, a despeito de seu acervo expressivo e das articulações encetadas com o sistema escolar, por meio do fortalecimento do sentido cívico de suas ações pedagógicas. 
23. O Consultório Sentimental de Madame Danjou: Experiências Femininas nas Ondas do Rádio

Caroline Cantanhede Lopes

Defesa: 31/08/2011 - Mestrado Acadêmico

Banca: Paulo Fontes (orientador), Angela de Castro Gomes (CPDOC/FGV), Lia Calabre (Fundação Casa de Rui Barbosa) e Bernardo Borges Buarque de Hollanda (CPDOC/FGV)

Resumo: Deocélia Vianna apresentou por um curto período, de 1952 a 1953, uma atração radiofônica intitulada Madame Danjou, que consistia em um programa de consultório sentimental, para o qual as ouvintes encaminhavam suas dúvidas através de cartas. Para as mulheres, o hábito de escrever cartas e diários não representou, ao longo dos anos, apenas uma peculiaridade feminina, $\mathrm{e}$ sim a possibilidade de expressão. Assim, em nossa análise sobre as demandas encaminhadas ao programa Madame Danjou, buscamos identificar elementos que nos permitam qualificar tanto as missivistas quanto a própria radialista como integrantes de um contexto específico, sem, no entanto, ignorar suas particularidades. Para tanto, consideramos o programa radiofônico como espaço de reflexão e sociabilidade para esses agentes sociais, devido ao fluxo de perguntas e respostas que o caracteriza. Antes, porém, não podemos perder de vista a trajetória particular de Deocélia Vianna, bem como as especificidades desse tipo de programa para compreendermos a outra ponta do diálogo que se estabelece: os conselhos. Também privilegiaremos a sua dimensão normatizadora, visto que tais conselhos eram direcionados para a remediação de conflitos do âmbito privado, via a adequação de determinados comportamentos.

\section{Ditadura e Fustiça Militar no Brasil: a atuação do Superior Tribunal Militar} (1964-1980)

Angela Moreira Domingues da Silva

Defesa: 0 7/10/2011 - Doutorado

Banca: Maria Celina D’Araújo (orientadora), Ludmila Ribeiro

(CPDOC/FGV), Dulce Chaves Pandolfi (CPDOC/FGV), Carlos Fico (UFRJ), Frederico Carlos de Sá Costa (UFF), Mario Grynszpan (CPDOC/FGV) e Renato Lemos (UFRJ)

Resumo: O presente trabalho tem como objetivo analisar a atuação do Superior Tribunal Militar(STM), segunda instância da Justiça Militar brasileira, entre os anos de 1964 e 1980. Desde a promulgação da Constituição de 1946, a função 
da justiça castrense era processar e julgar crimes militares e delitos contra a segurança externa, cometidos por civis e militares. No entanto, desde o golpe de 31 de março de 1964, o STM participou do processo de punição jurídico-política então instaurado, na medida em que passou a receber habeas corpus solicitados por pessoas presas e acusadas de subversão ou corrupção. Ao editar o Ato Institucional $n^{\circ}$ 2, em 1965, o governo Castelo Branco transferiu para a Justiça Militar o julgamento de crimes contra a segurança nacional, buscando reordenar problemas gerados pelo emaranhado legislativo que definia até então as atribuições do STM e do Supremo Tribunal Federal (STF) no julgamento de delitos vinculados à conjuntura política "revolucionária". Em virtude dessa nova atribuição, o volume de trabalho do STM aumentou sobremaneira, impactando seu comportamento ao longo da ditadura militar. Segundo a metodologia adotada neste trabalho, a Justiça Militar como um todo, e o STM em particular, atuaram nesse período por meio de três lógicas distintas: como Justiça corporativa (JC), ou seja, julgando crimes militares; como Justiça do regime (JR), direcionada para o processo e julgamento de opositores do regime, em casos de atentado contra a segurança nacional e contra a probidade administrativa; como justiça político-corporativa (JPC), julgando incriminados em delitos militares, mas por motivação política. Uma das contribuições que o trabalho oferece, ao estabelecer essas três vertentes de ação da Justiça Militar, é analisar a atuação do Tribunal, para além do viés político que caracterizou sua conduta durante a ditadura. Considerou-se que, além do monopólio de julgamento de temas relacionados à segurança nacional, ele manteve seu papel tradicional, ordinário, ou seja, de justiça corporativa. Ao longo da tese, buscou-se também acompanhar a maneira como o Tribunal se comportou frente às mudanças políticas e jurídicas que incidiram em sua estrutura e competência. Constatou-se que a utilização da produção legislativa, em geral originada no Poder Executivo, conjugada automaticamente à atuação do Tribunal, evidenciavam dificuldades em utilizar a cronologia política e as datas de edição das leis como recortes imediatos para entender a atuação do STM. Como mostra o trabalho, o impacto das leis sobre o labor do STM não foi imediato. A morosidade da justiça e a dinâmica processual geraram um descompasso temporal entre as propostas governamentais e os julgamentos. Uma das consequências diretas desse fenômeno foi o fato de o STM, principalmente ao atuar como Justiça do regime, ter que lidar, ao mesmo tempo, com leis de segurança nacional que se superpunham e coabitavam o mesmo campo jurídico, ao mesmo tempo em que o Estado policial, operacionalizado via órgãos de repressão, aumentava seu rigor persecutório. Verificou-se que o padrão decisório do STM, ao julgar em cada uma das categorias, tendia a reproduzir as decisões das Auditorias Militares, dado esse que nos permite relativizar a difundida tese de que o Tribunal atuou como um espaço de maior serenidade e complacência para com os condenados em primeira instância. 
25. "A sala de detidos": atuação e ascensão da polícia política da capital federal do Brasil, 1920-1937

Ângela Britto da Cunha

Defesa: 07/10/2011 - Doutorado

Banca: Marieta Ferreira de Moraes (orientadora), Lucia Lippi de Oliveira (CPDOC /FGV), Américo Freire (CPDOC/FGV), Luiz Reznik (PUC-RJ), Sérgio Guerra (Direito Rio/FGV), Surama Conde Sá Pinto (UFRRJ) e Dulce Chaves Pandolfi (CPDOC/FGV)

Resumo: Exploramos neste trabalho o desenvolvimento e a ascensão da função de polícia política da capital federal do Brasil, aqui compreendida como um mecanismo de proteção e manutenção do poder do Estado. Tomando por base as décadas de 1920 e 1930, procuramos investigar duas hipóteses. Primeiro, que nessa primeira década, o exercício de polícia política, a cargo da $4^{\mathrm{a}}$ Delegacia Auxiliar, pode ser tomado como o início do aperfeiçoamento da função. Segundo, que o decênio seguinte, ao ser marcado em seus primeiros anos por um processo de democratização das instituições brasileiras - que culmina com promulgação da Carta Constitucional de 1934, nos instiga à indagação sobre a necessidade do Estado contar oficialmente, a partir de 1933, com um órgão para o exercício exclusivo da função de polícia política. A análise contempla, a partir da legislação sobre a reorganização dos serviços policiais, da repressão social e política, e dos documentos produzidos pela polícia política, a relação entre o desenvolvimento desses órgãos e os eventos sociais e políticos no contexto nacional e internacional. Os pressupostos que nortearam o desenvolvimento dos órgãos de polícia política nas décadas enfocadas sugerem que a relação de exclusividade entre os mesmos e os regimes autoritários deve ser problematizada, ainda que a sua predominância nesses casos seja evidente, conforme nos mostra a própria história. Longe, contudo, de esgotar a discussão, buscamos oferecer elementos adicionais para o entendimento sobre a necessidade de o Estado manter uma polícia voltada à produção de informações visando ao acompanhamento de certos eventos sociais e políticos.

\section{Da emigração à diáspora galega: positivação de uma identidade}

Ana Paula Conde Lopes

Defesa: 27/9/2011 - Doutorado

Banca: Maria Celina Soares D’Araujo (orientadora), Luciana Quillet

Heymann (CPDOC/FGV), Mario Grynszpan (CPDOC/FGV), Marco Antonio Villela Pamplona (PUC-RJ), Monica Grin Monteiro de Barros (UFRJ), Lucia Maria Lippi Oliveira (CPDOC/FGV) e Santuza Cambraia Naves (PUC-RJ) 
Resumo: Este trabalho analisa as transformações ocorridas nas últimas décadas em relação à imagem dos emigrantes galegos e de seus descendentes. Por razões políticas inerentes à redemocratização espanhola, mas também em decorrência de novas análises conceituais acerca de minorias, identidades e nacionalidades, a imagem estereotipada do galego como emigrante pobre e ignorante foi revista, principalmente por parte do governo espanhol. Houve um reconhecimento positivado da galeguidade. Assim, o grupo desvalorizado, no início do século XX, passou a integrar uma "diáspora", que representaria a Galícia no mundo global do século XXI. Essa transformação obedece a movimentos nacionais da Espanha, como a implantação da política das autonomias, que reconheceu a Galícia como uma nacionalidade histórica, e a um contexto internacional marcado pela valorização das identidades e pela ampliação e flexibilidade do conceito de diáspora. Essa mudança acontece, também, tendo como base a grande rede de entidades associativas formada pelos galegos nos países para os quais emigraram. O objetivo do trabalho é apreender essa transformação que positiva um grupo antes considerado de segunda grandeza. Para tanto, a tese percorre vasta bibliografia sobre a emigração galega e recorre a vários autores que tentam explicar as razões e os resultados dessa emigração. Nosso ponto, contudo, é entender a reversão de expectativas ocorrida recentemente em relação "ao ser galego" buscando explicar de que forma contribuíram para tanto três atores fundamentais: o governo espanhol (e da Galícia); os emigrantes mundo afora, em suas rede associativas; e as transformações culturais e conceituais recentes acerca de identidades, nacionalismos, diáspora e direitos, entre outros.

27. A recuperação da informação sob a ótica dos usuários: um estudo de caso do uso da base de dados Accessus

Renan Marinho de Castro

Defesa: 29/9/2011 - Mestrado Profissional

Banca: Luciana Quillet Heymann (orientadora), Verena Alberti

(CPDOC/FGV), Lídia Silva de Freitas (UFF) e Mariana Cavalcanti (CPDOC/FGV)

Resumo: Trata das questões de organização e recuperação da informação no caso específico do acervo do Centro de Pesquisa e História Contemporânea do Brasil - CPDOC. Baseia essa análise num estudo de caso do uso do serviço de referência da instituição prestado pela Sala de Consulta e também no utilização da base de dados Accessus. Traça um perfil do usuário do acervo da instituição, além de um perfil de pesquisa desses indivíduos ao mapear o comportamento 
dos usuários diante da ferramenta Accessus. Aborda o contexto da elaboração da base de dados e investiga a criação da linguagem controlada em história e ciências afins que serviu de base para o Accessus. Problematiza as questões de acessibilidade da linguagem a um público não relacionado com a área. Pareia essa problematização com análise dos diferentes perfis de usuários. Discute a forma de indexação do acervo do CPDOC e suscita reflexões sobre esse processo que considerem uma relação direta com o perfil dos usuários. 